\title{
Pneumonitis during interferon and/or herbal drug therapy in patients with chronic active hepatitis
}

\author{
T. Ishizaki*, F. Sasaki*, S. Ameshima*, K. Shiozaki*, H. Takahashi*, \\ Y. Abe**, S. Ito**, M. Kuriyama**, T. Nakai*, M. Kitagawa ${ }^{+}$
}

\begin{abstract}
Pneumonitis during interferon and/or herbal drug therapy in patients with chronic active hepatitis. T. Ishizaki, F. Sasaki, S. Ameshima, K. Shiozaki, H. Takahashi, Y. Abe, S. Ito, M. Kuriyama, T. Nakai, M. Kitagawa. (CERS Journals Ltd 1996.

ABSTRACT: We report four cases of acute pneumonitis due either to interferon, or a herbal drug, "Sho-saiko-to", or both in combination, in patients with chronic active hepatitis, focusing on its pathogenesis and response to prednisolone therapy.

These cases shared common clinical features: fever, dry cough, dyspnoea, hypoxaemia, diffuse infiltrates both on chest radiography and chest computed tomography, restrictive pulmonary functional impairment, and alveolitis on examination of transbronchial lung biopsy, all of which suggest acute interstitial pneumonia. Furthermore, lymphocytosis was observed in association with the dominant CD8+ T-cell subset in bronchoalveolar lavage fluid. A lymphocyte stimulation test using peripheral blood was positive to interferon in one case and to Sho-saiko-to in another. All patients responded to oral prednisolone therapy. Peripheral soluble interleukin-2 receptor levels decreased in parallel with improvement in the clinical course. All patients were free of symptoms with a follow-up of 1-3 yrs.

We conclude that interferon- and/or Sho-saiko-to-induced acute pneumonitis may be due to allergic-immunological mechanisms rather than toxicity, and that peripheral levels of soluble interleukin-2 receptor appear to be good markers of disease activity.

Eur Respir J., 1996, 9, 2691-2696.
\end{abstract}

\begin{abstract}
*Third Department of Internal Medicine, and **Second Department of Internal Medicine, Fukui Medical School, Fukui, Japan. +First Department of Pathology, Toyama Medical and Pharmaceutical University, Toyama, Japan.
\end{abstract}

Correspondence: T. Ishizaki

Dept of Internal Medicine

Fukui Medical School

Matsuoka Cho

Fukui

Japan $910-11$

Keywords: Chronic active hepatitis herb drug

interferon

pneumonitis

soluble interleukin-2 receptor

Received: November 171995 Accepted after revision July 91996
Interferon, which is produced by virus-infected human cells, is recognized as having antitumour activity [1], and a modulatory effect on immune response, as well as antiviral activity [2]. Currently, interferon is divided into three subtypes: $\alpha-, \beta$ - and $\gamma$-interferon [3]. All three subtypes have been synthesized and used clinically against chronic active viral hepatitis [4], malignancies [5], or acquired immune deficiency syndrome (AIDS) [6]. However, side-effects, such as fever, myalgia, leucopenia, nephritis [7] and bronchiolitis obliterans organizing pneumonia (BOOP) [8] or pneumonitis [9-12] have been reported. The drug "Sho-saiko-to", a composite herbal preparation, has been popularly used for the treatment of chronic hepatitis in Japan [13], as it is reputed to protect liver cells against experimentally-induced damage in vitro, to enhance the induction of plaque-forming cells, to suppress the release of arachidonic acid and leukotriene $\mathrm{B}_{4}$ production [14], and to enhance interferon production by human peripheral blood mononuclear cells [15]. We describe the cases of four patients with chronic active hepatitis, who developed pneumonitis whilst being treated with interferon or Sho-saiko-to, or a combination of the two agents.

\section{Materials and methods}

Cell differentiation of bronchoalveolar lavage fluids (BALF) was performed by counting 500 cells stained with May-Giemsa dye after centrifugation, at $500 \mathrm{rpm}$ for $5 \mathrm{~min}$. Soluble interleukin-2 (IL-2) receptors (sIL2R) were evaluated by enzyme immunoassay of a cellfree IL-2R test kit (T-cell Sciences Inc., Cambridge, MA, USA). The normal range of serum sIL-2R in our laboratory from 40 healthy subjects was 301.5 \pm 56.6 $\mathrm{U} \cdot \mathrm{L}^{-1}$ (mean $\left.\pm \mathrm{SD}\right)$. Patient's heparinized plasma was used for the drug lymphocyte stimulation test (DLST); samples containing $1 \times 10^{5}$ cells $\cdot \mathrm{mL}^{-1}$ of lymphocytes per well were coincubated with $1 / 3,1 / 6,1 / 9,1 / 12,1 / 15$ and $1 / 18$ of $10 \mathrm{MU}\left(10^{6}\right.$ international units) interferon or with the same titres of $7.5 \mathrm{~g}$ Sho-saiko-to in the presence of $0.5 \mu \mathrm{Ci}^{3} \mathrm{H}$-labelled $\mathrm{TdR}$ at $37^{\circ} \mathrm{C}$ for 3 days. The results obtained were then compared with the corresponding control. A stimulation index higher than 1.8 was taken to be positive.

\section{Case reports}

\section{Case No. 1}

A 49 year old female with a 14 day history of dry cough and dyspnoea was admitted to our in-patient clinic. There was no fever or pretibial oedema. Chest physical examination revealed bilateral coarse crackles. Heart sound was normal, and electrocardiogram (ECG) demonstrated regular sinus rhythm. Plain chest radiography revealed diffuse reticulonodular shadowing associated with pleural effusion. Computed tomography (CT) showed 
Table 1. - Preceding therapy, BALF cell differentiation and DLST

\begin{tabular}{|c|c|c|c|c|}
\hline & \multicolumn{4}{|c|}{ Case No. } \\
\hline & 1 & 2 & 3 & 4 \\
\hline \multicolumn{5}{|l|}{$\begin{array}{l}\text { Preceding therapy } \\
\text { total dosage }\end{array}$} \\
\hline Interferon- $\alpha 2 b\left(\times 10^{6} \mathrm{IU}\right)$ & 272 & 506 & 700 & NT \\
\hline Sho-saiko-to g & 315 & 3400 & NT & 683 \\
\hline \multicolumn{5}{|l|}{ Bronchoalveolar lavage } \\
\hline $\begin{array}{l}\text { Nuclear cell count } \\
\left(\times 10^{6} \cdot \mathrm{mL}^{-1}\right)\end{array}$ & 4.8 & 12 & 6.8 & 1.5 \\
\hline Alveolar macrophage \% & 77.0 & 73.0 & 89.0 & 87.0 \\
\hline Eosinophils \% & 5.5 & 0.0 & 0.5 & 2.0 \\
\hline Neutrophils \% & 1.5 & 0.5 & 2.0 & 3.0 \\
\hline Lymphocytes \% & 17.0 & 26.1 & 8.5 & 8.1 \\
\hline $\mathrm{CD} 4+\%$ & 27.8 & ND & 46.5 & 4.2 \\
\hline $\mathrm{CD} 8+\%$ & 56.0 & ND & 35.3 & 91.1 \\
\hline \multicolumn{5}{|c|}{ Drug lymphocyte stimulation test } \\
\hline Interferon- $\alpha 2 b$ & -ve & -ve & $+\mathrm{ve}$ & ND \\
\hline Sho-saiko-to & -ve & $-\mathrm{ve}$ & ND & $+\mathrm{ve}$ \\
\hline
\end{tabular}

BALF: bronchoalveolar lavage fluid; DLST: drug lymphocyte stimulation test; -ve: negative; +ve: positive; ND: not done;

increased patchy density in the bilateral lower lung field. Laboratory data on admission showed: severe hypoxaemia (arterial oxygen tension $\left(\mathrm{Pa}, \mathrm{O}_{2}\right) 5.6 \mathrm{kPa}(42.2$ torr); moderately impaired vital capacity (VC $58 \%$ of predicted value) and transfer factor of the lung for carbon monoxide (TL,CO 54\% pred); and elevated C-reactive protein $\left(\mathrm{CRP} 2.45 \mathrm{mg} \cdot \mathrm{dL}^{-1}\right)$. No respiratory infection was apparent.

The patient had been treated with recombinant human interferon (IFN- $\alpha 2 b$ ) (table 1) and Sho-saiko-to, 7.5 $\mathrm{g} \cdot \mathrm{day}^{-1}$ for 6 weeks, following diagnosis of hepatitis C virus-induced chronic active hepatitis by serological findings and liver biopsy. The results of bronchoalveolar lavage (BAL) are presented in table 1. Cultures of sputum and bronchial washing were negative for bacteria, fungi and acid-fast bacilli (AFB). Transbronchial lung biopsies (TBLB) demonstrated interstitial infiltration by lymphocytes and mononuclear cells, as well as septal oedema and intra-alveolar exudate. Serum antibodies to human T-cell leukaemia virus (HTLV) and Trichosporon cutaneum (TC) were negative. DLST with peripheral blood was negative to IFN- $\alpha 2 b$ and to Sho-saiko-to. The patient's IFN- $\alpha 2 b$ and Sho-saiko-to treatment was stopped. Because of progressive dyspnoea and abnormal laboratory data, methylprednisolone pulse therapy was initiated $1 \mathrm{~g} \cdot$ day $^{-1} i . v$. for 3 days, followed by 4 days oral prednisolone, $40 \mathrm{mg} \cdot \mathrm{day}^{-1}$, twice over two weeks. A month later, the patient was free of dry cough and dyspnoea, an improvement which was associated with normalization of $\mathrm{Pa}, \mathrm{O}_{2}, \mathrm{CRP}$ and $\mathrm{VC}$, and so she was discharged. Soluble interleukin-2 receptor (sIL-2R) levels in plasma, which were elevated to $1,050 \mathrm{U} \cdot \mathrm{mL}^{-1}$ at the appearance of interstitial pneumonia (fig. 1), decreased after initiation of prednisolone therapy $\left(640 \mathrm{U} \cdot \mathrm{mL}^{-1}\right)$.

\section{Case 2}

A 59 year old male with a 2 month history of exertional dyspnoea was admitted to our in-patient clinic.

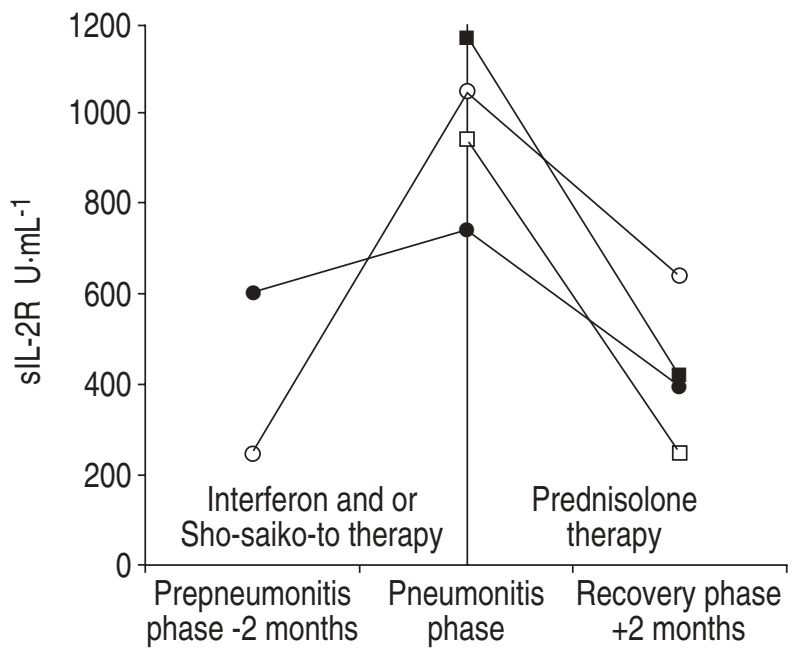

Fig. 1. - Sequential levels of serum soluble interleukin 2 receptor (sIL-2R) in four patients. Normal range of sIL-2R from 40 healthy subjects was $301.5 \pm 56.6 \mathrm{U} \cdot \mathrm{mL}^{-1}$ (mean $\left.\pm \mathrm{SD}\right)$. - - : Case No. 1, combination therapy; - - C Case No. 2, combination therapy; $-\square-$ : Case No. 3, interferon only; —- - Case No. 4, Sho-saiko-to only.

Physical examination revealed fine crackles around the lung field and a palpable liver. There was no fever or pretibial oedema. The chest radiograph revealed ground glass shadow on bilateral middle and lower lung fields (fig. 2). CT scan revealed patchy infiltrate in the middle lung zone. ECG demonstrated a regular sinus rhythm. Laboratory data on admission showed: mild hypoxaemia $\left(P \mathrm{a}, \mathrm{O}_{2} 9.7 \mathrm{kPa}\right.$ (72.6 torr); decreased VC (56\% pred) and $T \mathrm{~L}, \mathrm{CO}(34 \%$ pred); and elevated serum lactate dehydrogenase (LDH) activity (368 IU).

The patient had been treated with Sho-saiko-to, 7.5 $\mathrm{g} \cdot \mathrm{day}^{-1}$ for 15 months, following the diagnosis of hepatitis $\mathrm{C}$ virus-induced chronic active hepatitis by serological findings and liver biopsy. He had been treated

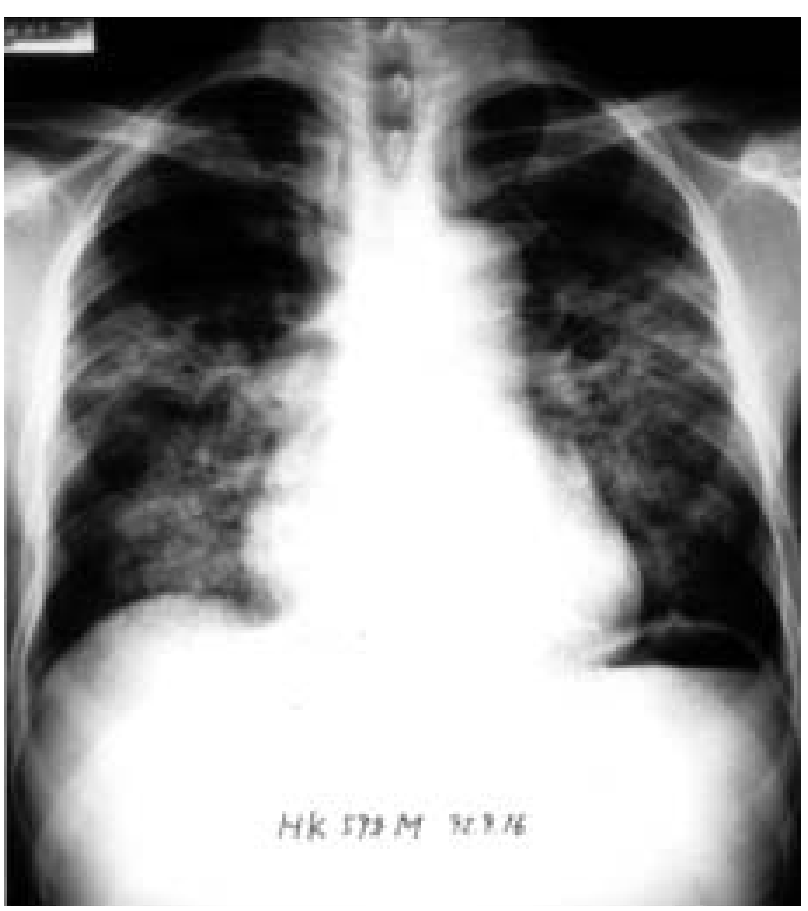

Fig. 2. - Plain chest radiographic image showing ground glass shadow on bilateral middle and lower lung field. 
with IFN- $\alpha 2 b$ for 1 month before experiencing dyspnoea. Serum antibodies to HTLV and TC were negative. BAL was performed at left $\mathrm{B} 8$, and the results are reported in table 1 . Cultures of sputum and bronchial washing yielded no bacteria, fungi or AFB. TBLB demonstrated a modest infiltration of lymphocytes and septal oedema suggestive of alveolitis. DLST was negative to IFN- $\alpha 2 b$ and Sho-saiko-to. However, IFN and herbal drug therapy were stopped. Oral prednisolone,

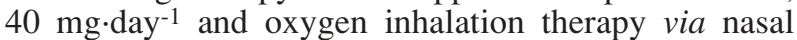
cannula $\left(4 \mathrm{~L} \cdot \mathrm{min}^{-1}\right)$ were initiated. One month later, the patient's symptoms had disappeared and improvement was confirmed in terms of $P \mathrm{a}, \mathrm{O}_{2}, \mathrm{VC}, \mathrm{CRP}$ and $\mathrm{LDH}$ activity. The plasma sIL-2R level, which was elevated to $744 \mathrm{U} \cdot \mathrm{mL}^{-1}$, had returned to normal ranges $\left(393 \mathrm{U} \cdot \mathrm{mL}^{-1}\right)$ after therapy (fig. 1).

\section{Case 3}

A 42 year old male was admitted to our in-patient clinic because of a 7 month history of dry cough, slight fever and dyspnoea. Physical examination on admission revealed tachypnoea ( 30 breaths $\cdot \mathrm{min}^{-1}$ ) but no rales on lung field. Plain chest radiography and CT scan showed patchy infiltrates on bilateral upper and middle lung fields, with elevated diaphragmatic position. ECG demonstrated regular sinus rhythm. Arterial blood gas analysis revealed severe hypoxaemia $\left(\mathrm{Pa}, \mathrm{O}_{2} 7.2 \mathrm{kPa}(54.3\right.$ torr)). There was no apparent respiratory infection and CRP was negative.

The patient had been treated with IFN- $\alpha 2 b$ (table 1) for the preceding 4 months following the diagnosis of hepatitis $\mathrm{C}$ virus-induced chronic active hepatitis from serological test and liver biopsy. BAL data are reported in table 1. Culture of sputum and bronchial washings were negative for bacteria, fungi and AFB. DLST was positive to IFN- $\alpha 2 b$, and IFN- $\alpha 2 b$ treatment was stopped. Oral prednisolone, $50 \mathrm{mg} \cdot \mathrm{day}^{-1}$, and oxygen inhalation $\left(2 \mathrm{~L} \cdot \mathrm{min}^{-1}\right)$ via nasal cannula were initiated. Dyspnoea disappeared promptly and chest roentgenological improvement was noticed. The patient was discharged and prednisolone, $10 \mathrm{mg} \cdot \mathrm{day}^{-1}$, was prescribed at out-patient clinic. Plasma sIL-2R receptor level, which was elevated to $944 \mathrm{IU} \cdot \mathrm{mL}^{-1}$ during interstitial pneumonia, decreased $\left(247 \mathrm{U} \cdot \mathrm{mL}^{-1}\right)$ after prednisolone therapy (fig. 1). Six months after initiation of prednisolone therapy, the patient was free of symptoms and no obvious abnormal shadow was noted on routine chest radiography.

\section{Case 4}

A 54 year old male was admitted to our in-patient clinic after a 10 day period of slight fever and productive cough. Chest physical examination showed no crackles. The plain chest radiograph revealed diffuse ground glass opacities. CT scan showed scattered diffuse increase in bilateral opacities (fig. 3a). Laboratory data revealed mild hypoxaemia $\left(\mathrm{Pa}_{\mathrm{a}} \mathrm{O}_{2} 8.2 \mathrm{kPa}(61.3\right.$ torr)), decreased TL,CO (59\% pred) and elevated serum glutamic oxalo-acetic transaminase (GOT) (147 IU), glutamic pyruvic transaminase (GPT) (223 IU), alkaline phosphatase (AIP) (743 IU), $\gamma$-glutamyl transpeptidase ( $\gamma \mathrm{GTP}$ (419 IU) and LDH activity (682 IU).
The patient had been treated with Sho-saiko-to, 7.5 $\mathrm{g} \cdot \mathrm{day}^{-1}$ for 3 months, following diagnosis of non-viralinduced chronic active hepatitis by liver biopsy and negative serological findings. BAL data from right B5 are reported in table 1. Culture of sputum and bronchial washings were negative for bacteria, fungi and AFB. Transbronchial lung biopsies demonstrated infiltration by lymphocytes and septal thickness compatible with alveolitis (fig. 3b). DLST was strongly positive to Shosaiko-to (to a component of Scutellariae radix). Serological test for HTLV and TC were negative. The herbal drug was stopped. Plasma sIL-2R level promptly decreased from $1,171 \mathrm{U} \cdot \mathrm{mL}^{-1}$ to $414 \mathrm{U} \cdot \mathrm{mL}^{-1}$ after initiation of prednisolone therapy (fig. 1). The patient was free of symptoms with a follow-up of 3 yrs.

\section{Discussion}

We have described four cases of interstitial pneumonia induced by treatment with interferon and/or the herbal drug, Sho-saiko-to, prescribed for chronic active hepatitis due to hepatitis $C$ virus infection. The four patients had no skin rash, no previous atopic disease or asthma, no respiratory infection, no preceding antibiotic therapy and no association with collagen vascular disease. They presented with common clinical features: dry cough; dyspnoea; fine or coarse crackle; restrictive pulmonary functional impairment; hypoxaemia; diffuse infiltrates on chest radiography and CT; and alveolitis suggesting interstitial pneumonia.

We consider that a positive peripheral DLST is further evidence of drug-induced pneumonitis [16]. To the best of our knowledge, one of our cases represents the second pneumonitis case (No. 3) published in the English language demonstrating positive DLST to interferon, and one (No. 4) the first case positive to a herbal drug. Interferon and Sho-saiko-to have been reported to be immunopotentiators [2, 15, 17], releasing some cytokines from fibroblast and mononuclear cells. Sho-saiko-to is a dried extract obtained from seven raw herbs: Bupleurum radix, Pinellia tuber, Scutellariae radix, Jujube fruit, Ginseng radix, Glycyrrhiza radix, and Ginger rhizome. Among these, Scutellariae radix activated peripheral lymphocytes in Case No. 4. Since Scutellariae radix contains baicalin, baicalein, wogonin, wogonin glucuronide, oroxylin-A, skull capflavone, chrysin, kaempferol, beta-sitosterol, camphesterol, sucrose and D-glucose, the substrate responsible for positive DLST could not be determined.

While we cannot elucidate the precise mechanism(s) of lung injury due to interferon and/or the herbal drug, elevated serum sIL-2R which reflects T-cell activation [18] may suggest T-cell abnormalities in the pathogenesis. At least monitoring of sIL-2R during any therapy involving interferon and/or Sho-saiko-to in patients with chronic active hepatitis may reveal activity towards interstitial pneumonia, since levels of sIL-2R parallel the clinical course.

Hitherto, there have been 6 cases of pneumonitis due to interferon therapy reported in the English literature [9-12]; all showed acute onset of dyspnoea with bilateral lung infiltration. All cases revealed interstitial pneumonia by histopathological examination, and the 3 
a)

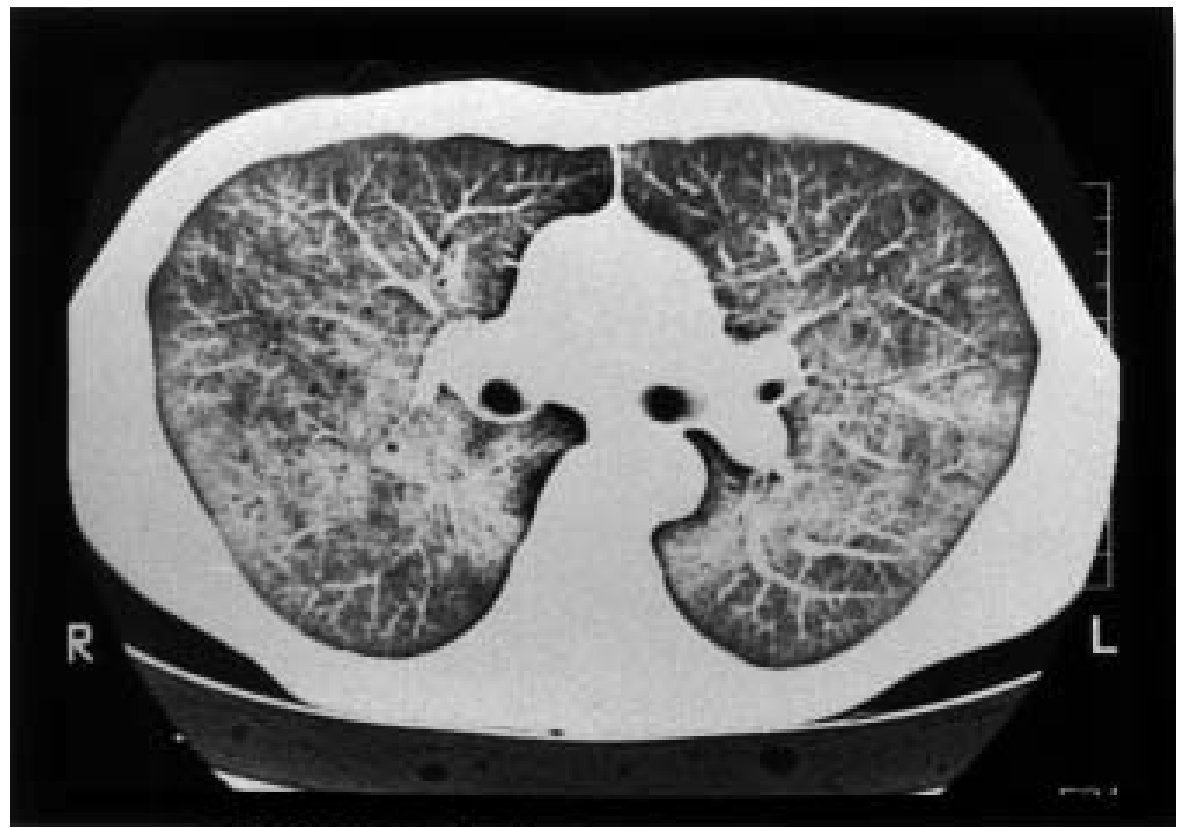

b)

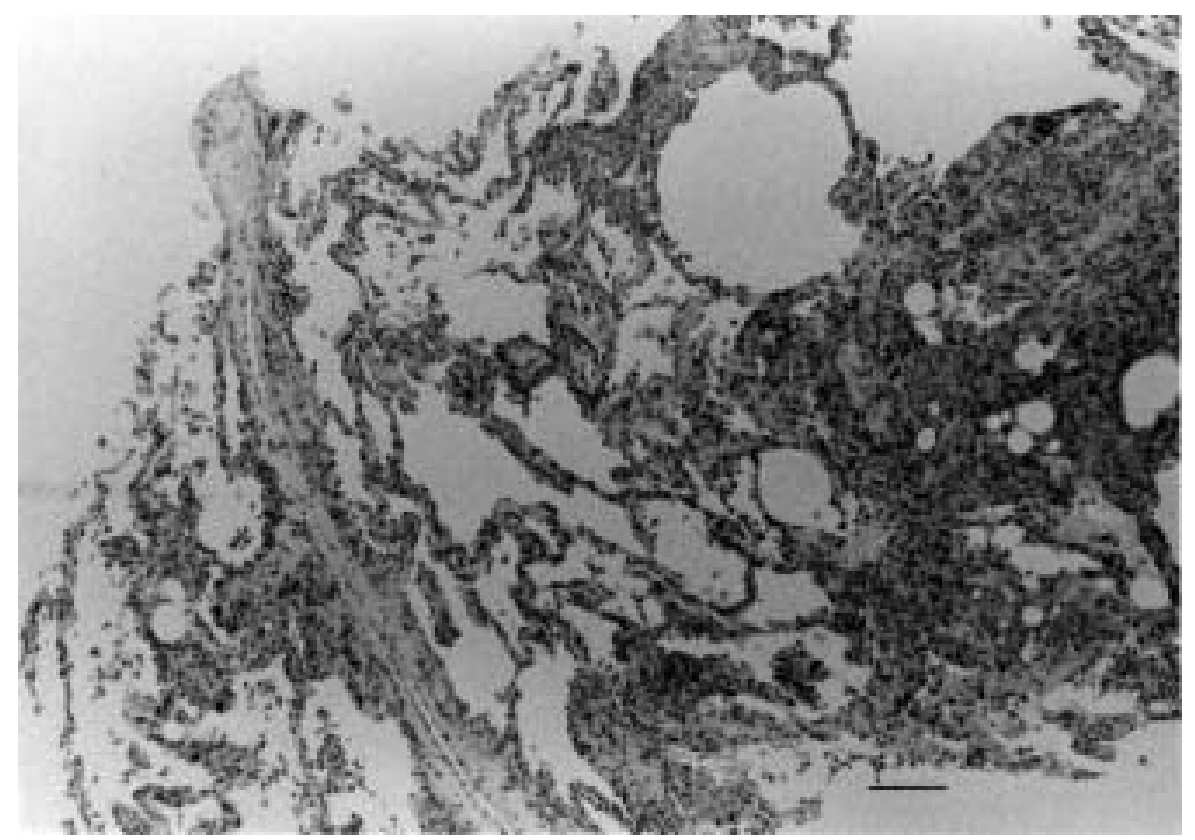

Fig. 3. - a) Chest computed tomographic scan, showing diffuse increased opacity. b) Transbronchial lung biopsy from right S8 segment demonstrating infiltration of lymphocytes and septal thickness. (Haematoxylin and eosin $(\mathrm{H} \& \mathrm{E})$ stain; original magnification $\times 100$; internal scale bar $=100 \mu \mathrm{m})$.

cases examined demonstrated increased numbers of lymphocytes with elevated CD8+/ CD4+ in BAL fluid (BALF). All recovered with prednisolone therapy $(n=5)$ or with cessation of interferon $(n=1)$.

It is currently estimated that there are about two million people in Japan suffering from chronic active hepatitis induced by hepatitis C viral infection. Since 1992, interferon therapy has been allowed for such patients with the support of health insurance from the Japanese Welfare Ministry. While interferon was used in combination with Sho-saiko-to for chronic hepatitis in Japan, 77 patients suffering from acute pneumonitis (31 cases received combination therapy) were reported by the Japanese Welfare Ministry by 1993 [19]. As a result, caution is currently recommended in the use of combination therapy with interferon and Sho-saiko-to for chronic active hepatitis.

Considering the increase in eosinophils in BALF (Case No. 1) and in peripheral blood (Case No. 4), and the increase in lymphocytes associated with elevated CD8+ cells in BALF (Case Nos. 1 and 4), and since interferoninduced BOOP was also reported [8], it is important to differentiate these cases from acute eosinophilic pneumonia, hypersensitivity pneumonitis and BOOP. Acute eosinophilic pneumonias [20,21], which present a febrile, rapid onset of respiratory symptoms and patchy lung infiltrate, commonly have increased eosinophil percentages in BALF (>20\%). In contrast, the maximum increase 
of BALF eosinophils in Case No. 1 was moderate $(5.5 \%)$, and the lung biopsy findings were not compatible with eosinophilic pneumonia. The most common hypersensitivity pneumonitis in Japan is the summertype hypersensitivity pneumonitis [22], which is caused by the inhalation of moulds containing Trichosporon cutaneum. Its essential diagnostic parameter is an increased number of lymphocytes (CD8+ cells) in BALF, characteristic histopathological findings and presence of serum anti-Trichosporon cutaneum antibody. None of our cases fit these criteria. BOOP, described by EPLER et al. [23], is a clinicopathological entity characterized by a granulation tissue plug within the lumen of the small airways extending into the alveolar ducts and the alveoli. The first report of interferon- $\alpha$-induced BOOP [8] was diagnosed by thoracoscopic biopsy. Although four of the present cases have a compatible clinical feature and image diagnosis, histopathological findings by TBLB did not report this diagnosis.

It is unclear why interferon and/or Sho-saiko-to induce pulmonary injury. In this context, it is interesting to note from recent reports that tumour necrosis factor (TNF) [24, 25], interleukin-2 (IL-2) [26-28] or granulocyte colony-stimulating factor (GCSF), a haematopoietic growth factor [29], have been shown to induce lung injury. TNF when used clinically in patients with cancer has caused impaired transfer factor [24, 25]. IL-2 also caused diffuse pulmonary infiltrate attributed to increased pulmonary capillary permeability, when administered to patients with advanced cancer [26-28]. Thus, TNF- and IL-2-induced pulmonary injury differ in pathophysiology from the present cases. GCSF, when used in the treatment of cytotoxic chemotherapy-induced neutropenia, causes interstitial pneumonia probably by augmenting subclinical pulmonary injury due to cytotoxic drugs [29]. The pathogenesis is speculated to be overproduction of the oxygen radical by an increased number of neutrophils sequestered by the lung, and does not fit the cases reported here.

Focusing on interstitial pneumonia, we refer to the report from UEDA et al. [30] in Japan that hepatitis C virus $(\mathrm{HCV})$ infection may play an important role in the pathogenesis of idiopathic pulmonary fibrosis because of an unusually high seroprevalence rate of anti-HCV in such patients.

Subsequently, the hypothesis was negated by IRVING et al. [31] in their study in patients with idiopathic pulmonary fibrosis from the UK. However, we cannot rule out the possibility of HCV infection as a predisposing irritant to the lung. All of the cases reported here responded well to prednisolone therapy in 1-2 months, again favouring allergic-immunological mechanisms rather than toxicity to the lung.

\section{References}

1. Lin SL, Kikuchi T, Pledger WJ, Tamm I. Interferon inhibits the establishment of competence in Go/S-phase transition. Science 1986; 233: 356-359.

2. Samuel CE. Antiviral actions of interferon: interferonregulated cellular proteins and their surprisingly selective antiviral activities. Virology 1991; 183: 1-11.

3. Stwart II WE, Blalock JE, Burke DC, et al. Interferon nomenclature. Nature 1980; 286: 110.
4. Davis GL, Balart LA, Sciff ER, et al. Hepatitis International Therapy Group. Treatment of chronic hepatitis C with recombinant interferon- $\alpha$ : a multicenter randomized, controlled trial. N Engl J Med 1989; 321: 1501-1506.

5. Quessada JR, Hawkins M, Horning S, et al. A collaborative phase I-II study of recombinant DNA-produced leukocyte interferon (Clone A) in metastatic breast cancer, malignant lymphoma, and multiple myeloma. Am J Med 1984; 77: 427-432.

6. Koech DK, Obel AO, Minowada J, Hutchinson VA, Cummins JM. Low-dose oral alpha-interferon therapy for patients seropositive for human immunodeficiency virus type-1 (HIV-1). Mol Biother 1990; 2: 91-95.

7. Averbuch SD, Austin III HA, Sherwin SA, Antonovych T, Bunn PA, Longo DL. Acute interstitial nephritis with the nephrotic syndrome following recombinant leukocyte $\alpha$-interferon therapy for mycosis fungoides. $N \mathrm{Engl}$ J Med 1984; 310: 32-35.

8. Ogata K, Koga T, Yagawa K. Interferon-related bronchiolitis obliterans organizing pneumonia. Chest 1994; 106: 612-613.

9. Kamisako T, Adachi Y, Chihara J, Yamamoto T. Interstitial pneumonitis and interferon-alpha. BMJ 1993; 306: 896.

10. Chin K, Tabata C, Satake N, Nagai S, Moriyasu F, Kuno $\mathrm{K}$. Pneumonitis associated with natural and recombinant interferon- $\alpha$ therapy for chronic hepatitis C. Chest 1994; 105: 939-941.

11. Murata M, Nagai M, Bando S, Dobashi H, Takahara J. Emergence of acute interstitial pneumonia following high-dose interferon-alpha treatment in a case of chronic myelogenous leukemia. Internal Med 1993; 32: 716718.

12. Yufu Y, Yamashita S, Nishimura J, Nawata H, Hirata J. Interstitial pneumonia caused by interferon-alpha in chronic myelogenous leukemia. Am J Hematol 1994; 47: 253.

13. Oda T, Oka H. Kampo preparations as biological response modifiers in the treatment of chronic viral hepatitis. In: Hosoya E, Yamamura Y, eds. Recent advances in the pharmacology of Kampo (Japanese herbal) medicines. Excerpta Medica International Series, No. 854. Tokyo, Excerpta Medica, 1988; pp. 369-377.

14. Mizoguchi Y, Sakagami Y, Okura Y, Yamamoto S, Morisawa S. Effects of Sho-saiko-to (TJ-9) in hepatitis patients and on the metabolism of arachidonic acid. In: Hosoya E, Yamamura Y, eds. Recent Advances in the Pharmacology of Kampo (Japanese Herbal) Medicines. Excerpta Medica International Congress Series, No. 854. Tokyo, Excerpta Medica, 1988; pp. 396-404.

15. Kakumu S, Fuji A. Effect of Sho-saiko-to (TJ-9) on interferon production by human peripheral blood mononuclear cells. In: Hosoya E, Yamamura Y, eds. Recent Advances in the Pharmacology of Kampo Japanese Herbal) Medicines. Excerpta Medica International Congress Series, No. 854. Tokyo, Excerpta Medica, 1988; pp. 378-385.

16. Halpern B, Ky NT, Amache N. Diagnosis of drug allergy in vitro with the lymphocyte transformation test. $J$ Allergy 1967; 40: 168-181.

17. Suganuma H, Sato A, Tamura R, Chida K. Effects of interferon-alfa and the herbal medicine Sho-saiko-to on cytokine production and lung fibroblast proliferation. Current Therap Res 1994; 55: 1551-1562.

18. Rubin LA, Nelson DL. The soluble interleukin-2 receptor: biology, function, and clinical application. Ann Intern Med 1990; 113: 619-627. 
19. Japanese Welfare Ministry. Report on Drug Side-Effect. No. 125, 1994.

20. Allen JN, Pacht ER, Gadek JE, Davis WB. Acute eosinophilic pneumonia as a reversible cause of noninfectious respiratory failure. $N$ Engl J Med 1989; 321: 569-574.

21. Umeki S. Re-evaluation of eosinophilic pneumonia and its diagnostic criteria. Arch Intern Med 1992; 152: 1913 1919.

22. Ando M, Arima K, Yoneda R, Tamura M. Japanese summer-type hypersensitivity pneumonitis: geographic distribution, home environment, and clinical characteristics of 621 cases. Am Rev Respir Dis 1991; 144: 765 769.

23. Epler GR. Bronchiolitis obliterans organizing pneumonia: definition and clinical features. Chest 1992; 102 $2 \mathrm{~S}-6 \mathrm{~S}$.

24. Kuei JH, Tashkin DP, Figlin RA. Pulmonary toxicity of recombinant human tumor necrosis factor. Chest 1989; 96: 334-338.

25. Schilling PJ, Murray JL, Markowitz AB. Novel tumor necrosis factor toxic effects, pulmonary hemorrhage and severe hepatic dysfunction. Cancer 1992; 69: 256-260.
26. Rosenstein M, Ettinghausen SE, Rosenberg SA. Extravasation of intravascular fluid mediated by the systemic administration of recombinant interleukin-2. J Immunol 1986; 137: 1735-1742.

27. Conant EF, Fox KR, Miller WT. Pulmonary edema as a complication of interleukin-2 therapy. AJR 1989; 152: 749-752.

28. Saxon RR, Klein JS, Bar MH, et al. Pathogenesis of pulmonary edema during interleukin-2 therapy: correlation of chest radiographic and clinical findings in 54 patients. AJR 1991; 156: 281-285.

29. Lei KIK, Leung WT, Johnson PJ. Serious pulmonary complications in patients receiving recombinant granulocyte colony-stimulating factor during BACOP chemotherapy for aggressive non-Hodgkin's lymphoma. $\mathrm{Br} \mathrm{J}$ Cancer 1994; 70: 1009-1013.

30. Ueda T, Ohta K, Suzuki N, et al. Idiopathic pulmonary fibrosis and high prevalence of serum antibodies to hepatitis C virus. Am Rev Respir Dis 1992; 146: 266268.

31. Irving WL, Day S, Johnston IDA. Idiopathic pulmonary fibrosis and hepatitis C virus infection. Am Rev Respir Dis 1993; 148: 1683-1684. 